\title{
CONNOTATIONS AS A FACTOR IN THE MENTAL HEALTH OF THE COMMUNITY.
}

\author{
By DONALD A. LAIRD, Iowa City, Iowa.
}

Recently Research Assistant, University of Iowa; Formerly Examiner, Psychiatric Unit, Great Lakes Naval Station.

I.

A few fortnights ago I was called in as friendly counsel regarding a situation which centered around a rapidly developing case of senile dementia. A theological student of promising ability had been forced to leave his studies somewhat prematurely and enter upon active ministerial work upon the death of his father which left him the sole support of his aged mother. He entered into the work of a rather responsible parish with vigor and enthusiasm but after a period of six months began to realize the deteriorating condition of his parent and the additional strain which this progressing condition was placing upon him.

The mother's orientation with respect to place, as well as time, was very defective, demanding an ever-increasing amount of attention. Excessive outbreaks of emotion and general irritability constantly and especially in public were not only trying but at times exceedingly embarrassing. The mother could not be left alone with safety for any length of time and the financial status would not permit of the employment of assistance, either trained or untrained. It was necessary for the son to be in almost constant association with his parent with but little time remaining to devote to the work of his parish.

The mother had slight recognition of her condition and the generally uncomfortable situation which resulted. The son's attitude was very frank and wholesome although in his management of the patient he did not manifest any unusual ability in the handling of psychiatric cases. In attempting to smooth down the emotional storms he had told his mother that unless she "braced up" and "got control of herself" it might become necessary to send her to a state institution. In a way these admonitions produced the desired result, but in a short time apparently became effective in the causation of a worried, fearful state of apprehension which was directed to the matter of commitment. This fretful attitude 
became more and more accentuated during the successive steps toward commitment until-but that is the starting point of this study.

During a conference with the son I learned that for several years the family had lived in Wisconsin in the vicinity of a county lunatic asylum. The more recent years of residence in Minnesota had been spent within the sphere of influence of a state asylum. These institutions with their frankly descriptive appellations had made a deep and unfavorable impression upon the present patient. It was this associative complex which was operative to a large extent in shaping the attitude of the mother toward institutional care. Accordingly arrangements were opened for the care of the patient in the Independence Hospital. The mother readily consented, in fact was eager to go since she had sufficient insight into her condition to realize that scientific supervision would be of benefit. She positively refused to willingly go near an asylum but would cheerfully enter a hospital. As soon as negotiations of which she was aware were entered into with the hospital her whole conduct, which had been dominated with the asylum. reaction until this time, changed for the better and the emotional outbreaks ceased for the time being. Remnants of a certain vague pride also remained and the term county and state were perhaps as influential in forming her aversion to the institutional names as were the terms asylum and lunatic. It was partly out of consideration for this barrier of pride-which is rather common as will be seen later-that the affective life became intensified. So the word state was omitted from the name of the hospital in all later reference to it and although the patient was aware of the fact that the institution was maintained by the state she was put at ease by the title given it.

This is just one case out of many in which the name of the institution plays a rôle by no means insignificant in determining the patient's conception of the institution and governing his receptiveness to the idea of care within its portals. Such cases as the above could be multiplied several fold, but it is doubtful if their importance can be unduly magnified.

Anyone who has made contracts with mental cases, in a professional capacity or otherwise, on the wards of institutions or in the family circle, can testify to the counteracting effects of the 
deplorable connotations bound up with certain terms which are in all too frequent use. The family physician can tell of the dolorific issue in the patient; the lawyer and the conservator know of the hesitancy in selecting an institution with a cognomen wholly or in part unpleasant. The psychiatric social worker comes up against antagonistic attitudes which have their origin in an antipathy to the institutional name and the associations which it carries. The resident psychiatrist is given the opportunity of tracing the delusional and affective structures which the patient erects as a natural reaction upon the wormwood of these chafing connotations and inner meanings.

In almost every phase of the world of commerce a happy term or a respected firm name means much to the success of an organization. Trade names have been copyrighted and capitalized and their use and ownership protected by the courts. The names of marketed products and commercial organizations have been demonstrated time upon time to possess a distinct value that can be measured, or at least estimated, in financial units.

When we turn to the field of mental health we also find that there is a scale of values consequent upon the associative context interwoven with terms which are in the long run synonymous. The relative value of these terms cannot be determined in monetary units as can the value of a trade name for these terms are cardinal in a realm which cannot be evaluated in terms of material things. Mental life and happiness are not to be purchased at any cost ; they are to be conserved and developed and valued for their own sake. And especially in this field is it that we find the connotations to be unusually strong and of such a nature as to exert an undesirable influence.

These symbolizations bound up with terms which in the past have been connected with objects now obsolete and repugnant have a very practical bearing upon community mental health. These unfortunate connotations are influential in determining the advance in community mental health in three important phases.

In the first place the attitude of the public in general toward the objects which are perhaps supreme in mental welfare is made sadly destructive by the use of terms which carry with them a rather rank and highly undesirable outer fringe of context. One of the first fruits of the labors of the National Committee for Mental Hygiene is the steady increase in the use of the term 
hospital to replace the more overtly descriptive terms which were predominant in this field only a few years ago. The cooperation of the body politic is essential for thorough and comprehensive results to be realized from efforts toward community mental health. This group factor cannot be wholeheartedly contributory so long as a considerable share of the terminology is laden with revolting and entirely unjustified filiations. And in passing it should be noted that those terms which carry the largest number of repugnant and antagonizing connotations are the ones with which the general public is most familiar and which are most productive in determining the group consciousness with reference to the things of mental health.

Consider this group consciousness boiled down, concentrated, and brought into the mental life of one as a vital, burning issue, coloring the entire stream of thought and conduct. Here is found a powerful force working in direct opposition to one of the outstanding aims of constructive mental hygiene. It is what is often found operative in what might be termed psychopathic material. At the one point in these individuals' lives where a wholesome, unbiased, healthy-minded attitude should be held toward the agencies of mental health we see the baneful results of the misconceptions of the ages as they are brought down to the present time in the associative conglomerate of connotations. The exacerbations in the symptomology and the appearance of transient secondary symptoms noticed in the newly admitted patient is frequently due in a large part to these undesirable affective connotations. In the case of voluntary patients undoubtedly these connotations are effective in lessening and delaying the applications. Where legal coercion is used to bring the patient for care and treatment the inner struggle is usually much greater than even the sometimes violent outward signs would indicate. Regardless of whether or not one is a Freudian the therapeutic significance of this emotional intensification is very apparent.

What may be isolated as the third mode of action upon community mental health is, like the second, really a derivative of the first but it is worthy of special consideration because of its direct effects upon the rehabilitation and the welfare of the ill of mind. I refer to the attitude often taken by the relatives and friends toward one who is receiving institutional care. This is 
active in the early stages of a case where a considerable hesitancy is shown about arranging for proper care and such a delay may seriously impair or even offset all later remediable measures. After the patient is at last placed in suitable surroundings the matter is not treated with openness, a marked reluctance is manifest toward visiting the patient because of the social connotations of the institutional name and the benefit which is to be derived in a large percentage of cases from properly timed and sincere visits is lost forever. Psychiatric social workers also tell me that they are not infrequently hampered in their work by attitudes taken by patients and relatives and which have root in the connotations of the terminology which in turn almost give justification to the uninitiated for their naive conceptions of work in mental health.

There is a decided need for a knowledge of the actual connotations which are present in present-day terminology as related to community mental health. Such a knowledge would enable one to estimate in a way the manner in which these associations are operative in various practical phases of work in public mental health. With such knowledge available it will also be possible to suggest any needed changes in the terminology which may be discovered. It is the object of this investigation to ascertain the nature and direction of the connotations in a limited number of terms which are in rather extensive use in this field.

There are many problems unique to work in public health which can be pushed nearer to a pragmatic solution by utilizing the methods of applied psychology in solving them. Commercial organizations have found applied psychology a valuable adjunct and it is to be reasonably expected that public health will also find such preliminary procedure a valuable auxiliary. The general approach which will be followed in the present report is that of applied psychology and any claim to originality must be limited to the application of these methods directly to the field of public mental health.

The most imposing bulwarks of the agencies of mental hygiene are the state hospitals for mental diseases. The names of these institutions are the ones with which the general public is most familiar and which are probably most influential in their connotations. The associative values of the various names taken by these institutions are, therefore, the main objective of the present 
investigation. Attention will be given only to the connotations of the names found among state hospitals for mental patients. There are several reasons for this limitation. These state institutions care for the bulk of mental patients; their influence also extends over a larger area than is the case with county and private or even municipal institutions. Private institutions are also excluded for the present because of the commercial nature which would attend the application of the findings. Private sanitaria, also, are not usually offensive in the matter of name-it is good business to have a title rich only in pleasant associations. Then, too, it is sort of a Hobson's choice; the present project had to be limited in scope that the task asked from our respondents might not be so difficult and involved as to destroy interest and cooperation.

II.

Before turning to the more empirical aspects of the present problem it is well that we orientate ourselves by a short survey of the development of the nomenclature in this field and acquaint ourselves with the present-day tendencies.

Tables I, II, and III were derived from the available data which gives the names of institutions of this character in full. ${ }^{2}$ In Table I the names of the institutions are reduced to the type categories indicated. The horizontal line of data, for example, which extends to the right of "Asylum, Insane" enumerates all institutions in which "Insane Asylum" seems to be the basic phrase. Such names are: State Insane Asylum, Asylum for the Insane, Asylum for Insane Indians, Northern Insane Asylum, etc. The other types enumerated are also considered as basic and the various institutional names placed in the horizontal line indicated by their essential elements. State Hospital for the Insane, for example, in view of our objective, obviously belongs under the category of "Hospital, Insane" rather than "Hospital, State."

${ }^{1}$ Data for $1880,1890,1903$, and 1910 is from the reports of the United States Census. Data for 1918 is from Pollock and Furbush: Comparative Statistics of State Hospitals for Mental Diseases, 1918. Mental Hygiene, 1920, 4, pp. 137-191. 
TABLE I.

Frequency of Type Names Among State Institutions for Mental Patients During Five Periods from i880 to 1918.

\begin{tabular}{|c|c|c|c|c|c|}
\hline \multirow{2}{*}{ Name. } & \multicolumn{5}{|c|}{ Period. } \\
\hline & 1880 & 1890 & 1903 & 1910 & 1918 \\
\hline \multirow[t]{2}{*}{ 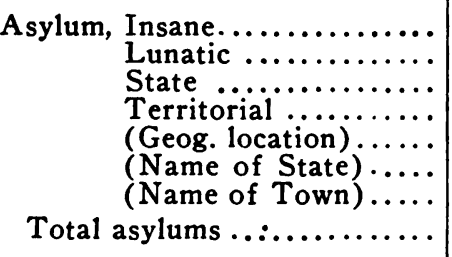 } & $\begin{array}{l}25 \\
15 \\
. \\
\because \\
\because \\
\because \\
. \\
\end{array}$ & $\begin{array}{l}42 \\
16 \\
\cdots \\
\because . \\
\cdots \\
\cdots \\
. \\
\end{array}$ & $\begin{array}{r}\text { II } \\
3 \\
2 \\
\text { I } \\
6 \\
4 \\
\text { I } \\
\end{array}$ & $\begin{array}{r}14 \\
1 \\
5 \\
. . \\
\because \\
2 \\
. . \\
\end{array}$ & $\begin{array}{c}4 \\
\mathbf{1} \\
\mathbf{3} \\
\therefore \\
\therefore \\
\therefore \\
\therefore \\
\end{array}$ \\
\hline & 40 & 58 & 28 & 22 & 8 \\
\hline \multirow{2}{*}{ 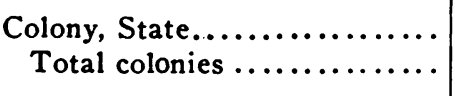 } & .. & .. & I & I & I \\
\hline & •. & $\cdots$ & I & I & I \\
\hline \multirow[t]{2}{*}{ 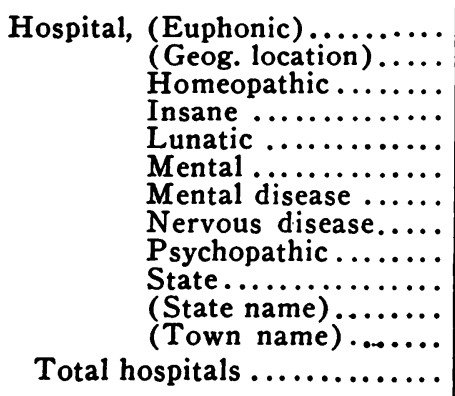 } & 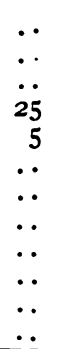 & $\begin{array}{l}\ldots \\
\cdots \\
39 \\
7 \\
. \\
\cdots \\
\cdots \\
\cdots \\
\cdots \\
. \\
.\end{array}$ & $\begin{array}{r}3 \\
20 \\
2 \\
8 \\
1 \\
1 \\
. \\
\cdots \\
\ddot{57} \\
8 \\
6\end{array}$ & $\begin{array}{r}2 \\
\because \\
\ddot{44} \\
1 \\
1 \\
1 \\
1 \\
1 \\
69 \\
\ddot{2}\end{array}$ & $\begin{array}{r}2 \\
0 \\
0 \\
30 \\
1 \\
1 \\
2 \\
1 \\
1 \\
104 \\
2 \\
2\end{array}$ \\
\hline & 30 & 46 & 106 & 122 & 146 \\
\hline $\begin{array}{l}\text { Infirmary, State............. } \\
\text { Total infirmaries } \ldots \ldots \ldots \ldots\end{array}$ & .. & $\ldots$ & . & I & I \\
\hline \multirow{2}{*}{$\begin{array}{l}\text { Retreat, for insane } \ldots \ldots \ldots \ldots \ldots \\
\quad \text { Total retreats } \ldots \ldots \ldots \ldots \ldots\end{array}$} & $\begin{array}{l}\cdots \\
. \\
\end{array}$ & $\begin{array}{l}* \\
I\end{array}$ & $\begin{array}{l}\ddot{ } \\
\ldots \\
\end{array}$ & $\begin{array}{l}1 \\
. . \\
\end{array}$ & $\begin{array}{l}1 \\
. . \\
\end{array}$ \\
\hline & . & I & $\cdots$ & . & $\cdots$ \\
\hline $\begin{array}{l}\text { Reformatory, The.............. } \\
\text { Total reformatories........ }\end{array}$ & .. & . & .. & . & I \\
\hline \multirow{3}{*}{$\begin{array}{l}\text { Sanitarium, State } \ldots \ldots \ldots \ldots \ldots \\
\text { Total sanitariums } \ldots \ldots \ldots \ldots \ldots \\
\text { Total institutions........... }\end{array}$} & $\begin{array}{l}\cdots \\
\ldots\end{array}$ & $\begin{array}{l}\cdots \\
.\end{array}$ & $\begin{array}{c}\cdots \\
I\end{array}$ & $\begin{array}{l}\cdot \\
I\end{array}$ & I \\
\hline & $\ldots$ & $\ldots$ & I & $I$ & $I$ \\
\hline & 70 & 105 & 136 & 147 & 159 \\
\hline
\end{tabular}

Analysis of this data reveals several significant tendencies. Two names, Colony and Infirmary, have come into use fairly recently, the former since 1903 and the latter since 1890 . The term Retreat as applied to state institutions has a transitory appearance 
in the period ending in 1890 . Sanitarium has been introduced into this field since 1890 and is showing some increase in use but not notably significant.

The most pertinent development, however, is in the shifting use of the terms hospital and asylum. In the case of the second term a steady decline in the number, and a much greater decline in

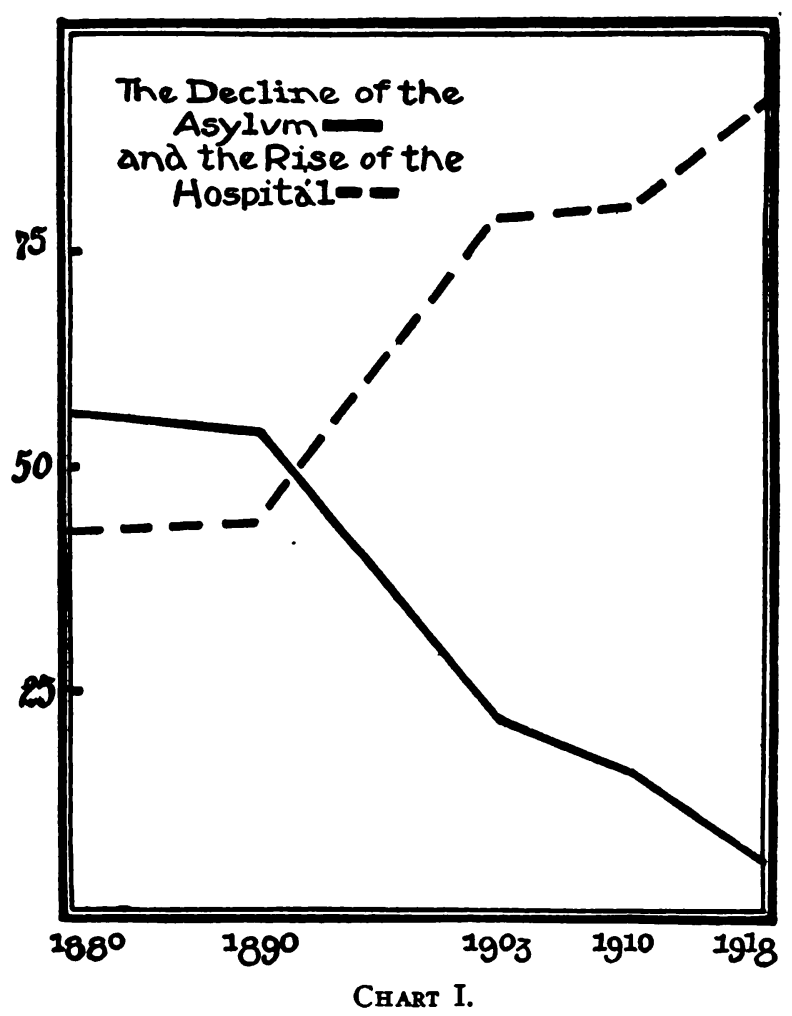

the per cent of institutions using this term as a part of their title is immediately noted. This decline is slight during the first per interim followed by a sudden drop from 55 per cent in 1890 to 20 per cent in 1903. The last two periods also record a decline in the use of this term but not nearly so marked as in the interval mentioned above. If the use of this term continues to diminish at the rate it has the last two periods it will be extinct in about 1o 
more years.' Reference to the sub-totals in Table I will suffice to indicate that the term hospital is replacing asylum, the curve of its ascent being almost the exact reverse of the decline of the asylum. This is plainly shown in Chart $I$ in which the periods are plotted on the horizontal and the per cent of institutions using the terms charted on the vertical scale which is on the basis of 0 to 100 per cent. In 1880 the distribution of these terms was about equal with a slight preference shown to asylum. At the close of 1918 all but 7 per cent of the institutions bore the name hospital.

A more detailed record of the institutional use of terms is given in Table II. The data for this table were obtained from the same sources as were used in Table I. In this instance, however, each of the major terms were recorded, no attempt being made to retain the type classification as was done in Table I. Insignificant terms such as of, for, the, and, at, etc., were not recorded. The terms have been divided into two groups, the generic and the specific. The generic terms specify the general character of the institution while the specific terms limit this meaning to one particular institution or at a certain place or of a specfic function or of a particular nature."

A marked characteristic to be noted upon even a superficial examination of this table is the abundance of specific terms. On the whole about two specific terms are used to one generic term. The specific terms most in use during the first period were insane, lunatic, state, and the names of states. In 1918 the terms found most in use are state, the names of towns, the names of states, and-strange as it may seem-insane.

The term state is used in both specific and what may be designated as sub-specific ways. For example we find State Hospital and State Insane Hospital. The names of towns, state names, and geographical terms are also used in the two ways mentioned.

${ }^{2}$ This applies to state institutions only. The decline in the use of this term among county institutions is probably very slight.

'Any apparent discrepancy between Tables I and II is dissolved by recalling that in Table $I$ the names were recorded under certain type categories. It will also be noted that the data under the generic terms in the present table is made up of the same number of terms found in the sub-totals of Table I. 
The term incurable has passed into oblivion in this immediate field " while chronic still persists as does also the term dangerous. During the last three years a slight increase in the use of homeo-

TABLE II.

The Use of Terms in Institutional Names.

\begin{tabular}{|c|c|c|c|c|c|}
\hline \multirow{2}{*}{ Terms. } & \multicolumn{5}{|c|}{ Period. } \\
\hline & 1880 & 1890 & 1903 & 1910 & 1918 \\
\hline 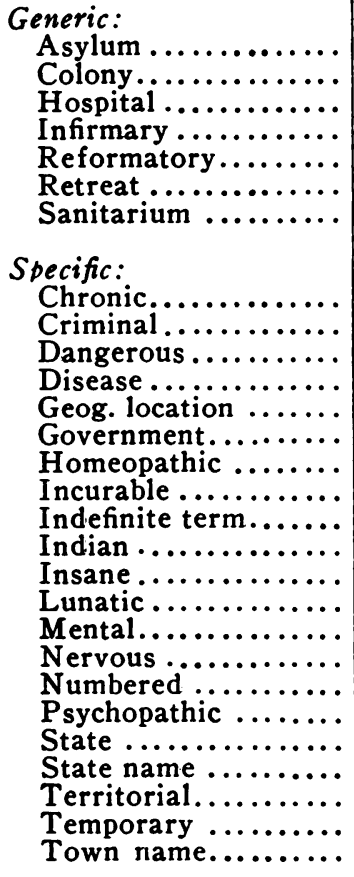 & 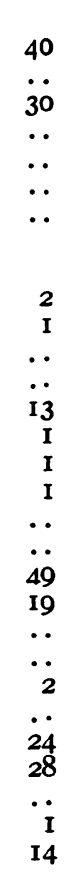 & 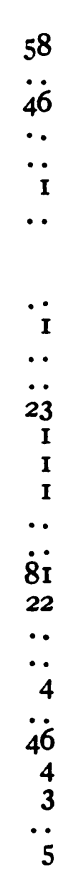 & $\begin{array}{r}1 \\
2 \\
1 \\
1 \\
38 \\
0 \\
1 \\
1 \\
3 \\
1 \\
20 \\
4 \\
1 \\
0 \\
5 \\
\ddot{7} \\
22 \\
1 \\
\ddot{3} \dot{8}\end{array}$ & $\begin{array}{r}1 \\
\ldots \\
\ldots \\
2 \\
28 \\
1 \\
2 \\
\ldots \\
2 \\
1 \\
60 \\
2 \\
2 \\
1 \\
5 \\
1 \\
96 \\
41 \\
1 \\
\ddot{6} \\
02\end{array}$ & $\begin{array}{r}\text { I } \\
\text { I } \\
\text { I } \\
3 \\
30 \\
\ldots \\
3 \\
\ldots \\
2 \\
\text { I } \\
34 \\
2 \\
3 \\
\text { I } \\
4 \\
1 \\
129 \\
34 \\
0 \\
\dot{82}\end{array}$ \\
\hline
\end{tabular}

pathic is observed. Psychopathic, and nervous, have appeared since 1903 while mental was already in use by that date. In both

"Just recently I passed a "Home for Incurables" in a large center. I must confess that the temperature of my spinal fluid lowered several degrees upon sight of this institutional name engraved in stone, apparently as ineradicable as the afflictions of those within the "home" were assumed to be. 
the generic and the specific terms an increase in variety is present in each progressive period. For example in 1880 there were 15 classes of terms in use, in 1903 there were 20 classes and 23 in 1918.

The terms most vital for our consideration are insane, lunatic, and state. Their use is graphically indicated in Chart II in which

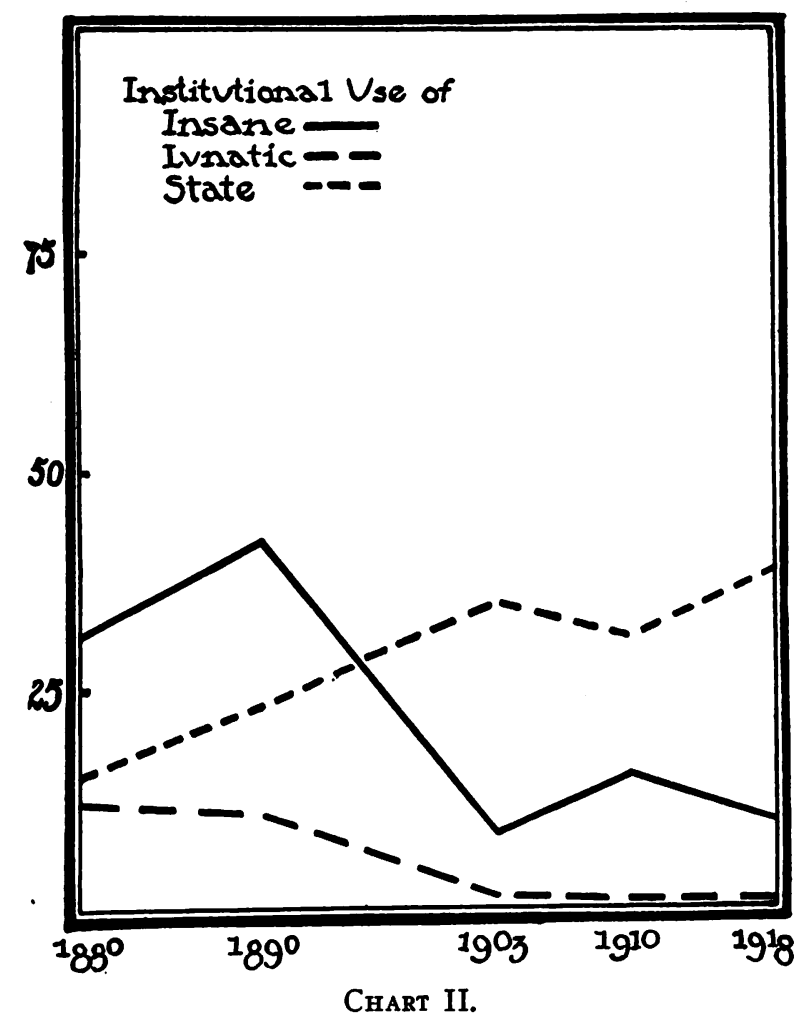

the census periods are again represented on the horizontal scale and the percentages of use on the vertical scale. At the opening period the term insane was over twice as popular as lunatic while state occurred with a slightly greater frequency than lunatic."

- It should be remarked at this point that in the earlier periods the term state was used almost entirely in a sub-specific sense. It usually appeared in connection with the specific term lunatic or insane while in 1918 the tendency was to use state as the sole specific term. 
An increase in the use of the term insane amounting to an absolute gain of II per cent is noted in I890 with a decline of about I per cent on the part of lunatic. During this same period state increases 8 per cent.

State continues to rise at about the same rate from 1890 to 1903 while there is a decline on the part of insane and lunatic, especially marked in the former. This decline in the use of insane is followed in the next period by an absolute increase of 6 per cent or a relative increase of almost 50 per cent. This rather unexpected and almost unexplainable finding was checked over institution by institution and was found not to be due to the entry of new institutions but to the change in names of old ones. Whether or not this is due to the source of data for $1903^{\circ}$ I cannot

TABLE III.

Number of Words Used in INStitutional Names.

\begin{tabular}{l|c|c|c|c|c}
\hline & 1880 & 1890 & 1903 & 1910 & 1918 \\
\cline { 2 - 3 } Number of institutions. & 70 & 105 & 136 & 147 & 159 \\
Total terms (Table II). & 226 & 297. & 350 & 455 & 493 \\
Average per name ..... & 3.2 & 2.8 & 2.5 & 3.1 & 3.1 \\
\hline
\end{tabular}

say but I am inclined to favor the view that in the reports for this period a connotative censorship was exercised to a certain extent One interesting observation to be made from Chart II is that the highest point of the curve for the use of state (I9I8) falls 3 per cent below the highest point in the curve of the use of insane ( 1890$)$.

It is apparent from the two charts so far presented that the most definite and marked development in the institutional use of terms in this field has been in the generic terms, asylum having been almost completely replaced by hospital. The development in the case of the specific terms is not quite so steady and definite and prediction in this respect is somewhat precarious.

It has already been noted that about two specific terms are in use for every generic term. In Table III is given the number

\footnotetext{
- United States Census: Special Reports, Insane and Feebleminded, I904. Washington, Government Printing Office, 1906.
} 
of words per institutional name, exclusive of prepositions, articles and connectives. The tendency is seen to be to use around three main words to a title. The periods ending in 1890 and 1903 made use of an average of about two ana a half words per name but the more recent tendencies as shown in the data for 1910 and 1918 is to use slightly more than three terms to a name.

Since the length of name is not touched upon in the experimental section it is well to consider this matter in slight detail at this point since it is of no little consequence. While it is not entirely a matter of connotations it may nevertheless be accepted as falling within the province of this work.

Long names are admittedly awkward to handle either verbally or in writing. They require an undue amount of time and attention and generally invite abbreviations and substitutes. Such popularly altered or substituted forms seldom, if ever, better the situation. The very common vulgarism "bughouse," deplorable as it is, among the staff and employees in general of state institutions is an instance at hand. A lengthy name composed largely of words of several syllables is sometimes considered to promote dignity and attract respect but the usual effect is just the opposite and rather than creating the desired results bulky names invite levity and ridicule. I doubt if there are any of my readers who will assimilate "The State Asylum for the Chronic Insane of Pennsylvania" without noting either a feeling of amusement or repulsion. Either reaction supports the point. If the name just given failed in any respect surely this which was found in the data for I880 cannot: "Asylum for the Benefit of Persons Bereft of the Use of Their Reason."

To anticipate the results of a later section it may be said now that while a lengthy name may be demanded for scientific accuracy of description it is much out of place to go into such specific detail for the general populace. To utilize these exact descriptions defeats to a very considerable extent their purported aims. In general, the shorter a name the more favorable will be its reception.

\section{III.}

Connotations as a factor in public mental health was set forth in Section I. The next section dealt with the objective situation of institutional names during five periods. In this section a report 
will be made of the methods and results of an empirical attempt to determine the subjective situation-that is, the relative connotative value of the various terms now in use or coming into use in this field.

By means of the data blank which is reproduced in Fig. I, the connotative value of the following terms was probed:

Generic terms:

Asylum.

Colony.

Indefinite term.

Hospital.

Infirmary.

Sanitarium.

Specific terms:

Disease.

Insane.

Indefinite term.

Lunatic.

Mental.

Nervous.

Name of a town.

Psychiatric.

Psychopathic.

For the preparation of the data blanks the generic term hospital was used as the basic or key term because it was anticipated that the presence of that term repeatedly would not have the discomforting effect which the other generic terms might produce. Reference to the reproduction of the data blank in Fig. I will show that the term hospital appears in combination with each of the specific terms. To determine the comparative connotative value of disease, however, it is introduced in combination with the term mental with which hospital has already been seen. The generic terms, with the exception of the indefinite term Sunnyside, are presented in combination with terms with which hospital is already found.

From the arrangement of the references as given by our respondents the values of the different terms, from the point of view of connotations, can be determined. In the case of the specific terms it is their combinations with the term hospital 


\section{Chicago Hospital}

\section{State INFTRMARY}

Riverview Hospital

Psychopathic Hospital

Mental Clinic

State Hospital

Lunatic Hospital

Psychiatric Colony

Mental Hospital

Nervous Hospital

Chicago Asylum

INSANE Hospital

Riverview Sanitarium

Psychiatric Hospital

\section{SunNyside}

Mental Disease Hospital

The two inside pages of this folder are vacant. On them write what it was about the different names that caused them to seem unpleasant or to be disliked. Write about as many of them as you can. Write as much about each one as you can. If there is not enough space inside to write all you want to use a separate sheet of paper and pin it to this.

\section{INSTRUCTIONS :}

Hospitals that treat mental diseases have many different names, although their aims and methods are practically the same. Some of these hospitals, however, have names which give an unfavorable impression. These names with unpleasant associations are very undesirable since it is an additional strain for one who is in danger of a mental breakdown to be sent for treatment to a place with a name that is disliked and perhaps repulsive.

It is the object of this folder to find out just what names cause the most aversion as well as those most liked.

Read over the list of names on the last page and in front of the name which to you seems to be the least unpleasant write the number I. In other words, which one of the hospitals would you choose on the basis of name alone in case it was necessary for you or some friend or relative to receive such treatment and care? Then, after you have made your first choice, look over the remaining names and write a 2 in front of the name next least objectionable to you. Continue until you have them all numbered. The name least objectionable will.be numbered $I$ and the name most objectionable numbered 16.

Do not discuss this with anyone until after you have filled in all the pages.

How old are you? ..................

Are you a man or a woman?

How far did you get in school ...........

What do you work at? ..................

In what state do you live? .............

FIG. I.-Blank used for collecting the data. The two inside pages of the folder are blank. The page illustrated to the right is page $I$; the page to the left is page 4 . 
which are crucial. To take an example, if we should find, by and large, that Riverview Hospital is preferred to Lunatic Hospital we should conclude that the connotative value of Riverview is better and more desirable from the approach of mental health than the connotations attached to lunatic.

With the generic terms it is the comparison of the preference ranks of the other generic terms which are combined with the same specific term which is crucial. For example, on the data blank the specific term Riverview is found in combination both with hospital and sanitarium. If, therefore, we find the average preference for Riverview Hospital to be three and the preference grade of Riverview Sanitarium to be I we would conclude that as a generic term sanitarium is to be desired over the term hospital, all other things being equal.

An objection, but by no means a fatal objection, to this method of evaluating the relative connotative values is that each generic term should be combined with all the specific terms. This is recognized as a theoretical consideration of some moment but I cannot see that it is of any great practical consequence. Admittedly it may be true that the general subjective effect produced by the specific term will vary slightly as the generic with which it is combined. The total situation connoted by Riverview Hospital may lend some enhancement to the specific term while the situation presented by Riverview Asylum subtracts some of the favorable associations from the same term. In general it is the absolute value which is not determined by this present procedure. The relative value, however, probably remains much the same within the specific series regardless of the generic partner so the pairs arranged in the data blank need not be increased several fold to pair all the generic and specific terms. A more serious defect which results from the presence of most of the generic terms only once is that they cannot be adequately compared with the basic term hospital. Practical necessity forces the present arrangement and to increase the number of entries on the data blank would obviously not only invalidate the results by setting a Herculean task for our respondents but also decrease the returns to a very low percentage.

A word of explanation concerning the motives which lead to the selection of the terms adopted with the neglect of others is 
appropriated at this point before going further into the experimental technique. To take up the generic terms first we find from reference to Table I that in 1918 six generic terms were in use. These were: asylum, colony, hospital, infirmary, reformatory, and sanitarium. The term reformatory was not used in the collection of our data since the denotation of this word eliminated it from the institutional type under consideration. The indefinite term Sunnyside which could be used as a name for a country house, a farm, a summer resort, or a health sanitarium as well as a state institution for mental patients, was introduced as a constructive suggestion prompted by a psychological analysis of the factors entering into the connotative complex in situations of the sort under investigation. Clinic was also used because it is a term which is coming into rather general use in other phases of community mental health activities.

Of the I7 specific terms reported for I9I8 only eight types were used in collecting our data. In general those appearing with the greatest frequency were selected although this criteria was not the sole basis for the choice. Some were omitted from our schedule because of denotative restrictions and other obvious inappropriateness. Such terms are chronic, criminal, dangerous, homeopathic, and Indian. Others of no great connotative significance such as the geographical location terms and numbers were left off the experimental list since the length needed to be restricted. The state name was not utilized on account of the introduction of extraneous associations. The term psychiatric while not in use by any state institution was introduced into the experiment because of the recognition which has been accorded to this term by several imposing public hospitals and clinics and the army and navy. When compared with psychopathic it will also give some insight into the relative merits of these oft debated terms.

Data was obtained from 422 respondents 'but for convenience of treatment (as well as ease of calculation) the number has been reduced to 400 . Eighteen incomplete returns were automatically eliminated and four others were discarded at random. The sex distribution of the respondents incorporated in this report is $23 \mathrm{I}$

\footnotetext{
'Especial acknowledgment should be made in this connection of the very valuable aid received from Professor Louvisa Wagoner of the University of Wyoming in securing a large part of this data.
} 
women to 169 men. It is a selected group, being composed in the main of persons with a high school education. The range of ages is from 18 to 66 years with the mode in the third decade. Preliminary tables showing preference by age, sex, and education were prepared but no essential variations were evidenced from the group findings other than those consequent upon a smaller number of cases being used. Accordingly these preliminary tables are omitted from this report.

The preferences of the 400 are tabulated in percentages in Table IV. In this table the frequency of each preference rank given to a name is indicated in per cents in the horizontal line of figures to the right of any given name. For example, 12 per cent of the respondents indicated Chicago Hospital as their second choice, 13 per cent gave this same term as their third preference, and so on.

Two prominent characteristics of the data to be seen upon a superficial observation of the general contour of this table is the grouping of the preferences for some of the terms at one end of the scale of preferences or a general scattering on the part of others. Riverview Hospital is an example of the distribution of the preferences throughout a rather narrow range primarily at the upper end of the scale. Insane Hospital illustrates the rather concentrated grouping in the lower or undesirable end. Psychopathic Hospital is distributed throughout all the preferences. This lack of unanimity, so to speak, of opinion is of some little practical importance as will be indicated more fully later.

There are several methods of treating the data which will be followed that we may be certain of our findings from several angles.

The connotative preferences, as recorded in Table IV, of the three most significant generic terms are charted in Chart III. In this chart, as in the charts which follow, the vertical represents per cents on a scale of $o$ to 100 and the horizontal the choices from first place to sixteenth. There can be no doubt as to the connotative merits of these three generic terms. The curve for asylum shows a lumping of choices toward the extreme lower end of the scale. Hospital occupies a somewhat similar position but at the upper or more desirable end of the scale of choices while the indefinite term Sunnyside is not only at the uppermost position but emphatically so. Both Asylum and Hospital show a seattering which is more marked in the case of the former. The indefinite 


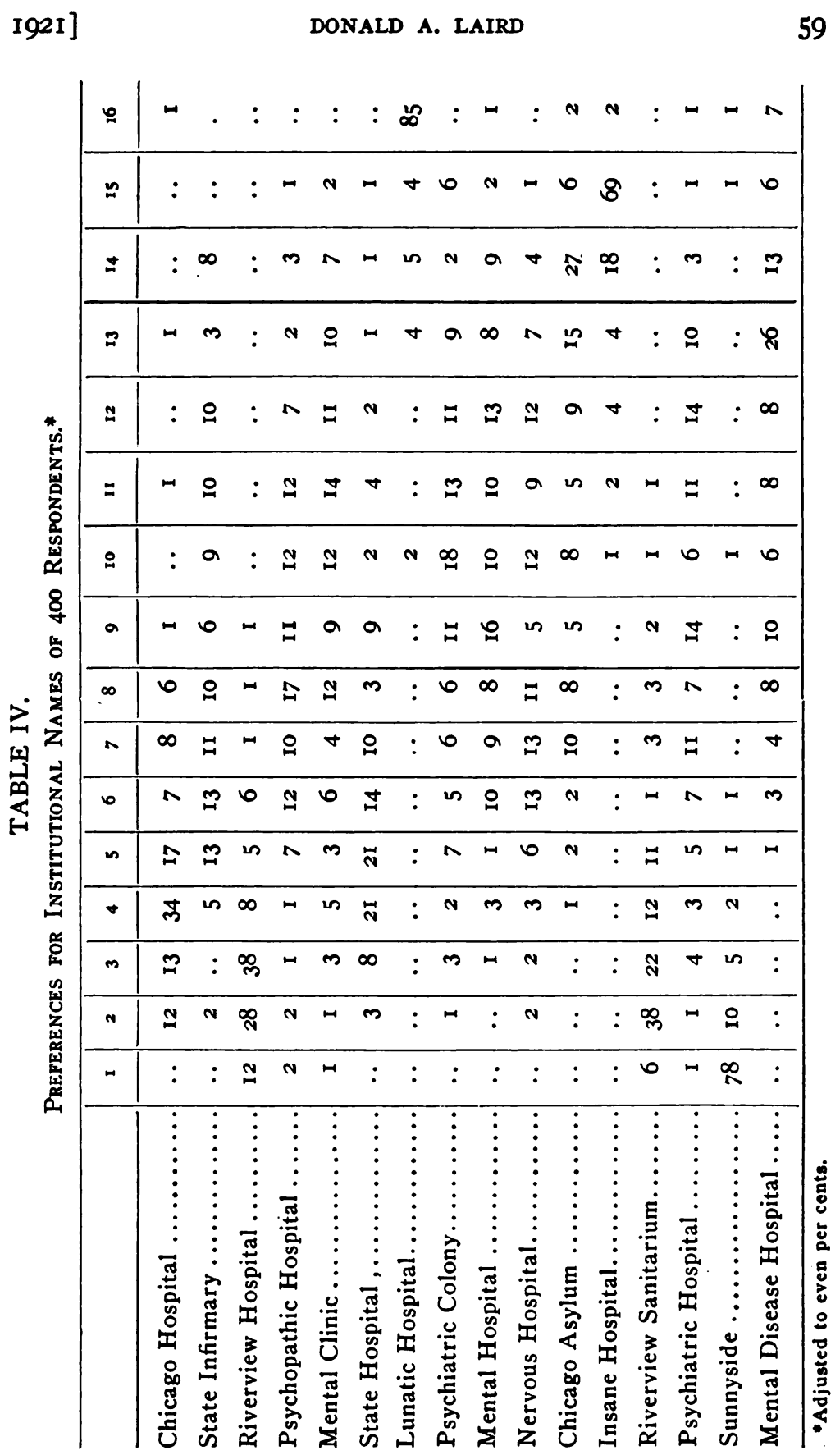


term, however, has a closely grouped and narrow range of choices, indicating a more general agreement on the part of our respondents.

In Charts IV and V the preferences for the more important of the specific terms are illustrated pictorially. Very definite tendencies are seen in the case of the first and last choices of this group, especially in the case of the latter where there is an extreme peak in the curve. The first preference is undoubtedly the indefinite term followed by the name of a town and the term state. The least preferred specific term is lunatic which is hard pressed by insane for the last place. Disease is also a contender for the last honors.

The fate of the remaining terms is not very evident from the graphs, in fact it will be noted that some of them are not recorded there. Accordingly a preference coefficient was developed to determine the position of terms such as psychiatric and psychopathic, nervous and mental which it is difficult to place on the charts. This coefficient penalizes each term one point for each per cent in each progressive displacement toward the lower end of the scale. The sum of these displacement-per cent products for each name, when divided by I00, the total per cent, will give the average placement of the name on the scale of choices. The formula for this in which $n$ represents the number of cases in each point on the scale of preferences indicated by the arabic numerals $I, 2,3$, etc., up to 16 would be:

$\frac{\mathrm{I} n^{1}+2 n^{2}+3 n^{3}+4 n^{4}+\ldots I \mathrm{I}^{4} n^{16}}{100}=$ Preference coefficient.

Applying this formula to the returns for each name we obtain the material for Table V.

TABLE V.

Preference Coefficients for the Names.

\begin{tabular}{|c|c|c|c|}
\hline Name. & Coef. & Name. & Coef. \\
\hline 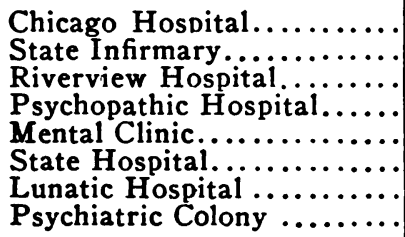 & $\begin{array}{r}479 \\
849 \\
299 \\
844 \\
952 \\
608 \\
1,562 \\
963\end{array}$ & 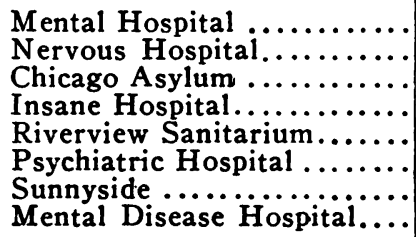 & $\begin{array}{r}981 \\
879 \\
1,143 \\
1,451 \\
341 \\
905 \\
173 \\
1,171\end{array}$ \\
\hline
\end{tabular}



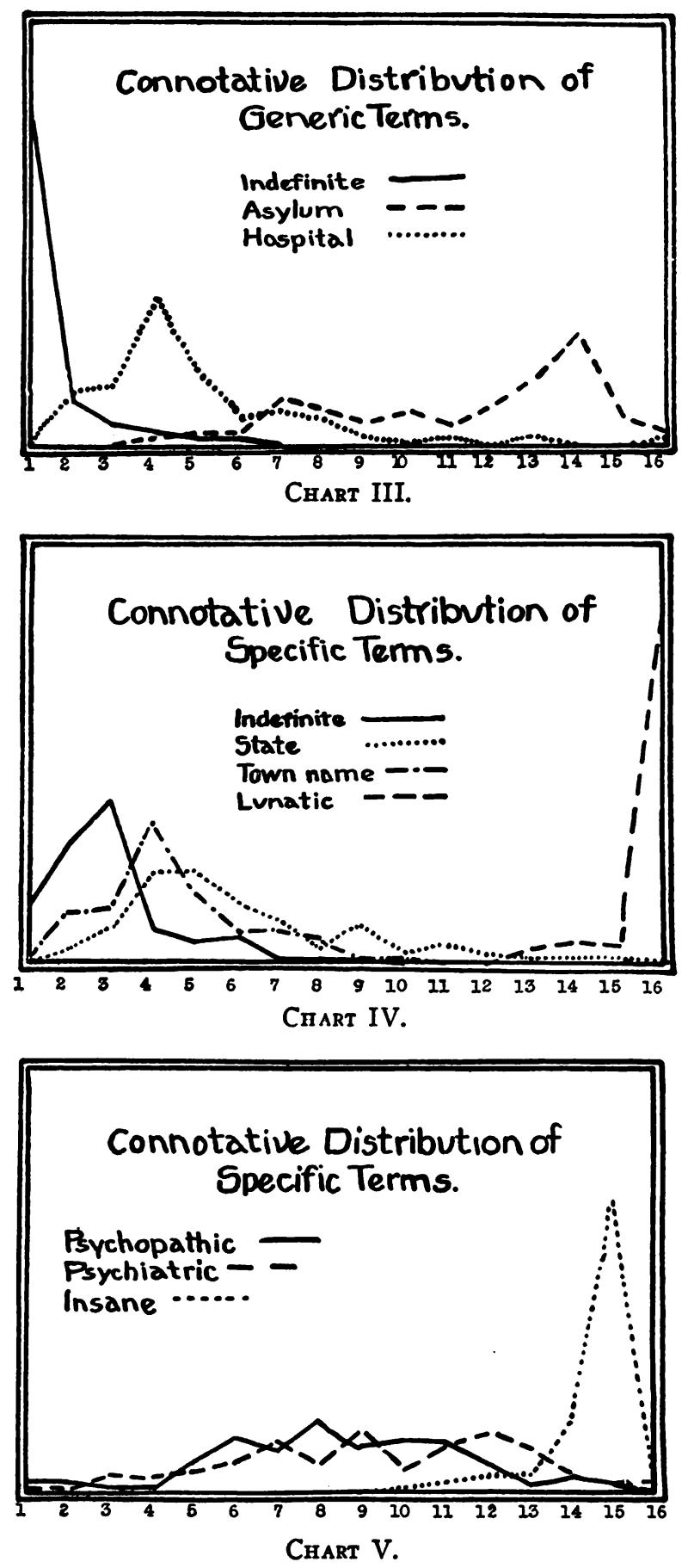
With the data reduced to coefficients as has now been done it will be possible to determine with some ease and reliability the relative connotative values of the terms, especially in the case of those terms from which there was a scattering of returns as psychopathicpsychiatric, where but little difference was apparent on the charts. Arranging the specific terms in the order of connotative merit as this coefficient permits we obtain the following series:

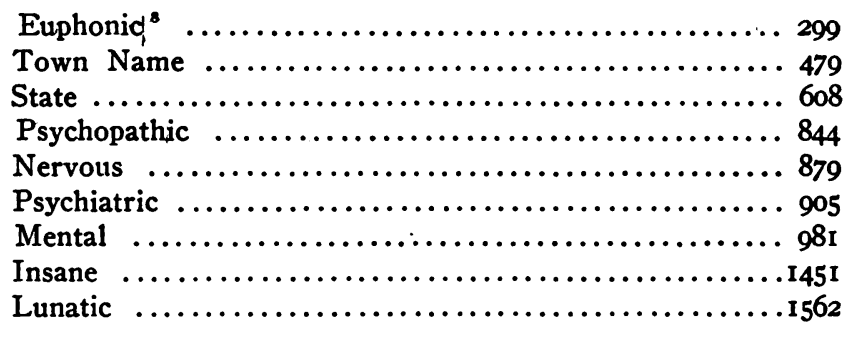

This order is very definite and plain and should call for little comment. It is to be noted, however, that psychopathic is connotatively as well as denotatively preferable to psychiatric. It is perhaps more significant that nervous is preferable by slightly more than 100 coefficient points to mental. Our respondents would apparently rather bear the burden of organic (nervous) disease than a disturbance of some ethereal, over-plus affair (mental). This preference is reflected also in the very common use of the vague phrase "nervous breakdown" to convey the idea that one has experienced a maladjustment of behavior. I believe, too, that this is. but another piece of evidence which indicates that the popular conception of "mind" is very similar to some antiquated theological conceptions of the same phenomena.

The conclusion to which we are forced by the data at hand regarding the specific terms is that, all other things being equal, from the approach of community mental health the most desirable terms are those least specific concerning the nature of the institution designated.

To arrive at the relative connotative value of the various generic terms it will be necessary, in addition to the charting of the most overt selections in Chart III, to compare the preference co-

' Riverview is the euphonic term used. 
efficients of the crucial pairs. Doing this we find the following data :

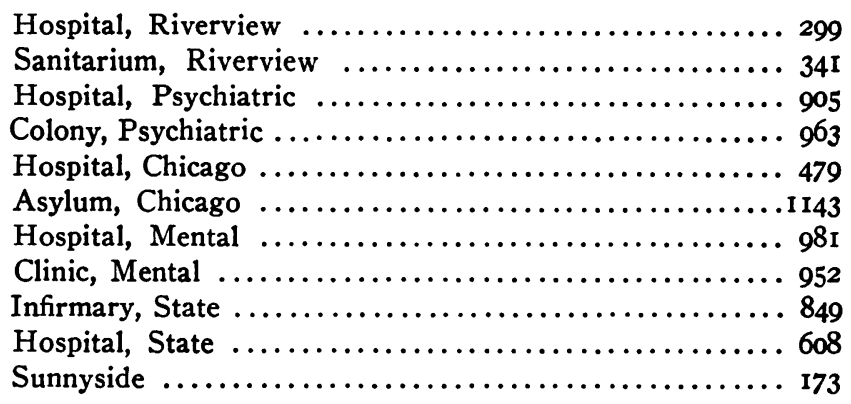

The generic term hospital is thus seen to be preferred largely through its connotative value to colony, sanitarium, infirmary, and asylum in the order listed. The preference of hospital over colony and sanitarium is very small but in the case of infirmary and asylum, especially in the latter, it is large enough to be of considerable significance. Clinic was the only generic term preferred to hospital but in this case also the difference is less than one step on our scale of $I$ to $I 6$. There are connotative restrictions on the use of clinic, however, which would make it seem best policy to retain the term hospital rather than clinic.

The one term which was obviously and conclusively demonstrated to be richest in desirable connotations was the indefinite, euphonic term Sunnyside which has a coefficient of 173 .

Apparently, in consideration of the above data, our conclusion regarding the use of the generic terms will simply be an echo of the findings regarding the specific terms. From the point of view of connotations the more indefinite a term the more desirable is its use.

Not only are the indefinite terms preferred in this connection but the thought of disease is better eliminated. Evidence of this is found in a comparison of the following preference coefficients:

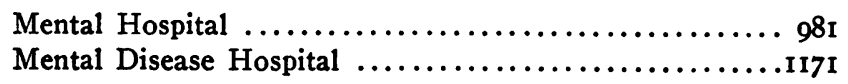

The introduction of the overt thought of disease thus is seen to throw the connotative value of a name from tenth place on our 
scale to twelfth place. A displacement of two steps toward the unpleasant and more undesirable end of the scale. With the exception of Sunnyside the disease aspect probably enters into the connotative complex of all the generic terms but in not so marked a manner as in this one instance.

One of the first observations made upon the data of Table IV was that some of the preferences spread out over practically all 16 points while in other cases the preferences were concentrated at one extreme of the other. The range of preferences thus furnishes the material for Table V'T.

Only in one instance above do we find a scattering throughout the entire scale. This is in the case of the term psychiatric. Psy-

TABLE VI.

The Range of the Preferences.

\begin{tabular}{|c|c|c|c|}
\hline Name. & Range. & Name. & Range. \\
\hline 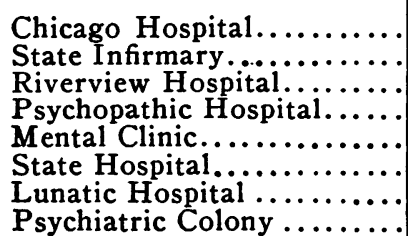 & $\begin{array}{r}11 \\
12 \\
9 \\
15 \\
15 \\
14 \\
5 \\
14\end{array}$ & 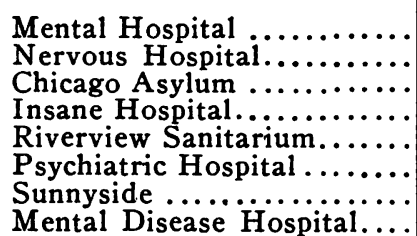 & $\begin{array}{r}14 \\
14 \\
13 \\
7 \\
11 \\
16 \\
9 \\
12\end{array}$ \\
\hline
\end{tabular}

chopathic is found in all choices but one-the last. Nervous, mental, and state are distributed throughout 14 of the possible 16 places. Referring back to page 62 where the specific terms are found arranged in the order of connotative merit we note that the terms with the most scattering are those found between the extremes in the connotative order. Those which either head the list or are found at the bottom are the ones in which the range is smallest. Riverview, for example, has a range of nine and is found at the head of the connotative arrangement At the other extreme of the scale is insane with a range of seven and lunatic with a range of five. The most decisive results of this study are apparently in a negative direction, least variation in connotative selection being manifest in the most undesirable terms.

It would of course be extravagant to think that the associations carried by any given term or phrase would be practically identical 
for all people. There can be no doubt, however, that there are terms on which there is a general agreement. The data in the instance of lunatic seems to indicate this strongly. All other things being equal or even nearly equal the terms for which there seems to be most definiteness of connotative trends should be given preference over those with scattering associations. To carry this into action would be to avoid the institutional use of the terms for which the apperceptive mass, so to speak, is variable thus eliminating automatically those terms with a range of more, say, than nine.

The reasons given by our respondents for preferring certain terms over others confirms the frequently occurring observation that, regardless of whether man is a rational animal or not, most of man's profoundest and most certain convictions are not conceived by a logical inspection. A large number of those who contributed to the data which has been reported stated in unequivocal terms that there was a great significance attached to the various names on the data blank. While no one was able to state the reasons for this adequately they were nevertheless very positive in their preferences. The practical value of the findings is in no way lessened by the nebulous connotations which the respondents attempted, but failed, to identify.

In most instances "....... is better than ......." or "I do not like ......." were stated as the reasons for their preferences. The fundamental trends influencing and forming the connotations of these terms is apparently deep lying in the mental life and not on the surface ready for instant examination. This would lend support to the contention that the matter of the connotations of the institutional names is of no little significance in community mental health.

A statement which was written very frequently by the respondents was that they were led to select a given name as first choice because it did not in any way suggest the real nature of the institution. The present generation is very loath to admit the presence of that most estatic of human experiences-mental disease. Sunnyside was thus given first rank to a large extent on account of its indefiniteness and partly because of the pleasant imagery it brings to mind. This same term was also placed last in the range of preferences by some who objected because an institution of this kind, so they said, was really not nearly so pleasant as the 
name would lead one to think and to use so agreeable a term was almost plain deceit. Not exactly deceit but perhaps camouflage and that of a very wholesome sort. Lunatic and insane brought to mind the very prevalent conception of despair, hopelessness, ravings, and all the conventional popular attributes of the non mens compos. State smacked of charity to numerous of the correspondents.

To a few people hospital was repulsive because of painful experiences but on the whole was accepted as standing for scientific efficiency. Clinic suggested a very thorough examination and adequate treatment at the hands of several experts, carrying the hospital concept perhaps more concentrated than does the term hospital. Infirmary was associated almost invariably with exhausted forces and debility as was colony which also savors of isolation and lepers. An air of distinction and luxury is carried by sanitarium but it is also clouded by charlatanism.

Psychopathic and psychiatric were elected primarily upon their capacity to be pronounced. To most of the communicants they were comparatively meaningless terms and neutral in their connotative effects otherwise than suggesting some medical diseases. Psychiatric was especially meaningless and pronounceless. I believe that on the whole the terms preceding psychopathic in the list of connotative merit as given on page 62 have desirable connotations, those following psychiatric undesirable connotations. The range between and including these terms is probably, by and large, relatively neutral.

IV.

In the two preceding sections we have studied the institutional nomenclature as it is and as it should be from the point of view of connotations. In the present section we will attempt the somewhat onerous and difficult task of superimposing the results of the two previous sections that we may in a way measure up and compare the ideal with the actual. It is sort of a connotative diagnosis which will be the aim of this section. To carry the medical analogy further, after having made the diagnosis some practical indications within the institution itself will be resolved.

We found that there has been a persistent decline in the use of the generic term asylum which is being replaced by the term hos- 
pital recalling the relative connotative values of these two terms this may be described as a healthy tendency. Hospital also was found to dominate the field of terminology at the present day. This condition, also, is in itself in harmony with our connotative findings in general. Hospital does carry the disease aspect rather prominently, however, and was found connotatively to be inferior to a less definite and more euphonic term.

In the matter of specific terms we found in section two that the rather common tendency now is to use the term state as qualifying hospital. In our empirical findings, on the other hand, the term state is found third from the top (page 62). It is more desirable to use either a euphonic term or a town name rather than state. The difference in this case as was experimentally determined is about four steps on the preference scale used and is large enough to be significant. A gracious natural selection is at work eliminating the more rankly undesirable specific terms. What is needed now is a conscious selection in the adaptation of a terminology that will better serve the functions of these institutions.

In the light of our findings in section third, one might ask: Why have a specific term at all? And the question is very pertinent. We have found from our experimental material that indefiniteness is to be desired but before commending the application of this criterion in a wholesale manner to institutions for mental patients it may be well to anticipate involvements in respects other than connotative. The chief objection which may be raised against the adoption of a less definite, even generic, terminology is that the general public must be "educated up " until a more wholesome attitude toward mental ill-health is attained and to introduce terms that are not concrete and specific and are not a part of a technical vocabulary already existant will impede this progress considerably. It is entirely possible to cause such a change in attitude on the part of the great majority as Isben would say it. We see examples of such an accomplishment in the instance of large corporations which suffered a loss of public confidence upon exposure under the anti-trust laws. By extensive- and expensive-morale advertising it has been possible for them to win back the public confidence in due time.

As I see it there are two courses open with respect to this terminology as it is a factor in community mental health. The one 
would be to start in with a clean slate by adopting terms more consistent with the interests of mental hygiene such as was determined in the section inmediately preceding. The other course would be to win the public confidence to the terminology now in use.

Either course is practical. The first is perhaps the easiest of accomplishment. A great deal has already been done to approach the latter by the National Committee for Mental Hygiene but such progress is only in its infancy. It is entirely possible for the two courses to be interlocked to a certain extent thereby gaining the most from the start. It is one duty of the institutional executive as well as every isolated worker in this field to lend every effort to the upbuilding of a more rational terminology as well as gaining more of the public confidence and good will. The so-called mass mind is very plastic and fickle and in the hands of conscientious workers much can be accomplished in moulding it along any line desired. The influence of the state institution extends over a large radius and it is as much the function of these monuments to mental maladjustment to be a constructive force in the upbuilding of community mental health as in the rehabilitation of the patients in their care. So long as a part of the terminology fostered by these institutions is in itself destructive through its associations public policy will be loath to accept a healthy minded attitude toward the things of mental hygiene. 